\title{
PANORAMA BRASILEIRO DA RELAÇÃO ENTRE LEPTOSPIROSE E INUNDAÇÕES
}

Francisco Carlos Portela ${ }^{1}$ Masato Kobiyama ${ }^{2}$ Roberto Fabris Goerl ${ }^{3}$

Resumo: A leptospirose é uma das doenças de veiculação hídrica que mais preocupam o setor de saúde no Brasil. Portanto, o objetivo deste artigo foi, por meio de levantamento de trabalhos existentes, identificar, analisar e descrever os fatores socioeconômicos, ambientais e climáticos que podem estar diretamente relacionados ao aumento dos casos de leptospirose. Além disso, o presente trabalho fez uma análise temporal e espacial, demonstrando a relação entre publicações e casos/óbitos no Brasil. Por meio de pesquisa nas bases de dados de periódicos CAPES e LILACS, o presente trabalho selecionou 43 artigos que trataram de leptospirose e inundações no Brasil. A maior parte desses trabalhos relacionou a ocorrência de eventos hidrológicos extremos ao aumento do número de casos de leptospirose. Os demais trabalhos relacionam outros fatores como acúmulo de resíduos, falta de drenagem urbana, atividades laborais, entre outros

Palavras-chave: Leptospirose. Saúde pública. Inundações. Brasil.

\section{BRAZILIAN PANORAMA OF THE RELATIONSHIP BETWEEN LEPTOSPIROSE AND FLOODS}

Abstract: Leptospirosis is one of the waterborne diseases that strongly concern the health in Brazil. Therefore, the objective of the present study was to identify, analyze, and describe the socioeconomic, environmental, and climatic factors that can be directly related to the increase of the leptospirosis cases. In addition, the present study carried out a temporal and spatial analysis to demonstrate the relationship between publications and cases-deaths in Brazil. By searching the databases of the CAPES and LILACS, we selected 43 papers that dealt with leptospirosis and flood in Brazil. Most of the evaluated papers related the occurrence of extreme hydrological events to the increase in the number of cases of leptospirosis. The others focused other factors such as waste accumulation, lack of urban drainage, working services, and so on.

Keywords: Leptospirosis. Public health. Floods. Brazil.

\section{PANORAMA BRASILEÑO DE LA RELACIÓN ENTRE LEPTOSPIROSIS Y INUNDACIONES}

Resumen: La leptospirosis es una de las enfermedades de transmisión hídrica que más preocupan al sector de salud en Brasil. Por lo tanto, el objetivo de este artículo fue, por medio de levantamiento de trabajos existentes, identificar, analizar y

\footnotetext{
${ }^{1}$ Universidade Federal de Santa Catarina, Programa de Pós-Graduação em Desastres Naturais, Florianópolis, Brasil, francisco.geosc@gmail.com, https://orcid.org/0000-0003-4718-0961

2 Universidade Federal do Rio Grande do Sul, Departamento de Obras Hidráulicas, Porto Alegre, Brasil, masato.kobiyama@ufrgs.br, https://orcid.org/0000-0003-0615-9867

3 Universidade Federal de Santa Catarina, Departamento de Geociências, Florianópolis, Brasil roberto.f.goerl@ufsc.br, https://orcid.org/0000-0001-6261-7143
} 
describir los factores socio-económicos, ambientales y climáticos que pueden estar directamente relacionados con el aumento de los casos de leptospirosis. Además, el presente estudio realizó un análisis temporal y espacial para demostrar la relación entre publicaciones y casos-muertes en Brasil. Por medio de investigación en las bases de datos de revistas CAPES y LILACS, el presente trabajo seleccionó 43 artículos que trataron de leptospirosis e inundaciones en Brasil. La mayor parte de estos trabajos relacionaron la ocurrencia de eventos hidrológicos extremos al aumento del número de casos de leptospirosis. Los demás trabajos relacionan otros factores como la acumulación de residuos, falta de drenaje urbano, actividades laborales, entre otros.

Palabras clave: Leptospirosis. Salud Pública. Inundaciones. Brasil.

\section{Introdução}

A ocorrência de inundações é frequente no Brasil, provocando impactos como perdas humanas e de bens materiais (TOMINAGA et al., 2009). Do total de 31.909 desastres naturais registrados entre 1991 e 2010 no país, as inundações e enxurradas corresponderam a 33\%. Estes eventos resultaram em 1.567 óbitos, 309.529 lesionados ou doentes, 1.812 desaparecidos e 3,5 milhões de pessoas impactadas (CEPED, 2012).

De maneira geral, as populações mais vulneráveis tendem a ocupar áreas propensas a inundar. Estas localidades apresentam, geralmente, precárias condições de saúde e saneamento e uma situação de desastre natural tende a agravar circunstâncias socioeconômicas já críticas, acarretando o surgimento de doenças de veiculação hídrica (COSTA et al., 2001). Segundo Aleixo e Neto (2010), as mudanças climáticas podem provocar aumento significativo na incidência de uma grande quantidade de doenças transmitidas pela exposição à água ou alimentos contaminados, pelo contato com animais ou pela aglomeração de pessoas afetadas e desalojadas, como, por exemplo, diarreias, leptospirose, malária, dengue, entre outras. Dentre essas doenças, uma que possui relação com a ocorrência de inundações é a leptospirose (LONDE et al., 2016), que é uma doença bacteriana, infecciosa, febril e aguda, ocorrendo principalmente em regiões tropicais como o Brasil. É causada por uma bactéria do gênero leptospira interrogans presente na urina de ratos, que quando dispersa no ambiente, pode se misturar às águas provocando contaminação e o contágio.

Em épocas de fortes precipitações e consequentes inundações, problemas na distribuição de água potável, o acúmulo de resíduos e presença de esgotos abertos, resultantes da falta de saneamento e da urbanização desordenada, acabam favorecendo a reprodução de vetores e hospedeiros (BARCELLOS e SABROZA, 
2001; SANTOS et al., 2012). A água exerce um papel primordial na transmissão da leptospirose; quando ocorrem inundações, enxurradas e alagamentos, a leptospira atinge locais que comumente não são propícios a sua ocorrência, como localidades com melhores condições de saneamento e onde estão presentes grandes contingentes de indivíduos suscetíveis à doença (TASSINARI et al., 2004).

As consequências da incidência desta doença podem se estender por um longo período, provocando preocupantes impactos nas comunidades atingidas. Oliveira et al. (2009) observam que a leptospirose é uma zoonose com alto índice de letalidade $(9 \%)$, necessitando de políticas públicas de prevenção do setor de saúde. Conforme Santos et al. (2012), a leptospirose pode afetar a economia devido ao elevado custo financeiro das internações hospitalares e aos impactos nas transações comerciais de produtos de origem animal, além de dificultar a vida produtiva dos indivíduos infectados. No Brasil, há poucas pesquisas sobre a temática, se levarmos em consideração que foram registrados 63.302 casos dessa zoonose entre 2000 e 2016, ou seja, cerca de 4.000 casos/ano (MINISTÉRIO DA SAÚDE, 2017). Nestes 17 anos, a doença foi responsável pela morte de 6.064 pessoas. O maior número de casos foi registrado nas regiões Sudeste (21.633) e Sul (20.343), seguidos pelas regiões Nordeste (11.198), Norte (9.198) e CentroOeste (930). Os estados com maior número de óbitos pela doença confirmados foram São Paulo (1.554), Rio de Janeiro (793), Pernambuco (563), Rio Grande do Sul (449) e Bahia (331).

Diante dessa situação preocupante para a saúde pública, o objetivo do presente trabalho foi, por meio de levantamento de artigos científicos publicados desde o ano 2000 até o ano 2017, identificar, analisar e descrever estudos que relacionaram a ocorrência de casos de leptospirose com as inundações no Brasil. A partir desse levantamento, foram apontados temas que necessitam de pesquisas mais específicas, tais como políticas de habitação e inclusão social, aumento da cobertura de saneamento básico, entre outros tópicos relevantes. Além disso, o presente trabalho fez uma análise temporal e espacial, demonstrando a relação entre publicações e casos/óbitos no Brasil.

\section{Metodologia}

A revisão da literatura sobre leptospirose no Brasil foi realizada por meio de pesquisa nas bases de dados CAPES e LILACS. Estas bases foram escolhidas devido à importância e abrangência nos índices de literatura científica e técnica da 
América Latina e Caribe. A base LILACS reúne, ainda, informações sobre a área da saúde. A pesquisa, realizada em junho de 2018, contemplou os seguintes descritores: Leptospirose e Inundação; Leptospirose e Desastres; Leptospirose e Enchentes; Leptospirose e Cheias; e Leptospirose e Brasil. Os termos foram buscados tanto em inglês como em português, contudo, foram selecionados apenas estudos restritos ao território brasileiro. O presente estudo pesquisou diferentes terminologias associadas ao processo de inundação, pois há, na literatura, uma falta de consenso sobre a mesma (GOERL e KOBIYAMA, 2005).

O critério adotado para a seleção de artigos foi: estudos restritos ao território brasileiro, independente do idioma (inglês/português), com abordagem da relação leptospirose e inundações (cheia ou enchente), ou seja, ambos os assuntos deveriam ser tratados em conjunto no estudo. De cada artigo encontrado foram analisados título, resumo, palavras-chave e resultados. Após está primeira análise, os artigos que se enquadraram no critério adotado foram separados por ano, região geográfica e principais resultados. Tais informações foram relacionadas à distribuição espacial de casos confirmados e de óbitos, e discretizadas por unidade da federação.

Os dados obtidos relacionados ao número de casos confirmados e óbitos por leptospirose foram coletados, em maio de 2018, do banco de dados do SUS/DATASUS (http://datasus.saude.gov.br), do Ministério da Saúde. O período analisado para todos os objetivos e análise dos resultados foi de 2000 a 2017. Os dados foram tabulados e analisados no Excel e os mapas e as análises espaciais realizadas no QGIS.

\section{Resultados e Discussão}

No portal de periódicos da CAPES, com os descritores "Leptospirose e Brasil", havia até a data da consulta, 397 publicações. Já com os descritores "Leptospirose e Desastres" foram encontradas 28 publicações. A busca por "Cheias e Leptospirose" resultou em 10 artigos, "Enchentes e Leptospirose" em 38 publicações e "Leptospirose e Inundações" resultou em 25 trabalhos.

A busca na base LILACS resultou em 71 trabalhos para os termos "Leptospirose e Inundação" - no entanto, nem todos são estudos com enfoque no Brasil. Os termos "Brasil e Leptospirose" apontaram para 496 estudos, enquanto que "Leptospirose e Enchentes" e "Leptospirose e Desastres" 86 estudos cada. A Tabela 1 apresenta os resultados por termo pesquisado. Observa-se que, apesar da grande 
incidência de inundação e leptospirose no Brasil, estes temas estudados em conjunto ainda não são expressivos. Nota-se também a falta de consenso na questão da terminologia do desastre, sendo o termo "enchente" ainda o mais frequente.

Tabela 1 - Pesquisa por palavra-chave nas bases CAPES e LILACS.

\begin{tabular}{lcc}
\hline & LILACS & CAPES \\
\hline Leptospirose + Brasil & 496 & 397 \\
Leptospirose + Desastres & 86 & 28 \\
Leptospirose + Inundações & 71 & 25 \\
Leptospirose + Cheias & 20 & 10 \\
Leptospirose + Enchentes & 86 & 38 \\
\hline Total & $\mathbf{7 5 9}$ & $\mathbf{4 9 8}$ \\
\hline
\end{tabular}

Fonte: Elaborado pelos Autores

Analisando as duas bases de dados tem-se um total de 1.257 artigos indexados, sendo que a base LILACS reuniu a maior parte deles, 759 publicações, enquanto o Periódico CAPES somou 498. Do total de artigos, 70 publicações foram consideradas, a priori, elegíveis para o estudo. Contudo, de acordo com o objetivo de analisar a relação direta entre inundações e leptospirose, foram selecionadas 43 publicações (Figura 1). Grande parte dos outros artigos encontrados apresentou aspectos como estudos ecológicos, de diagnóstico, clínicos, ocorrência não humana, custos econômicos, levantamento sorológico, variação sazonal, entre outros. Alderman et al. (2012), ao realizarem uma revisão sistemática sobre inundação e saúde humana, encontraram resultados semelhantes. Pesquisando bases de dados internacionais, estes autores encontraram cerca de sete mil artigos, dos quais apenas 35 apresentaram relação direta ente saúde e inundação. 
Figura 1 - Etapas e critérios das análises bibliográficas

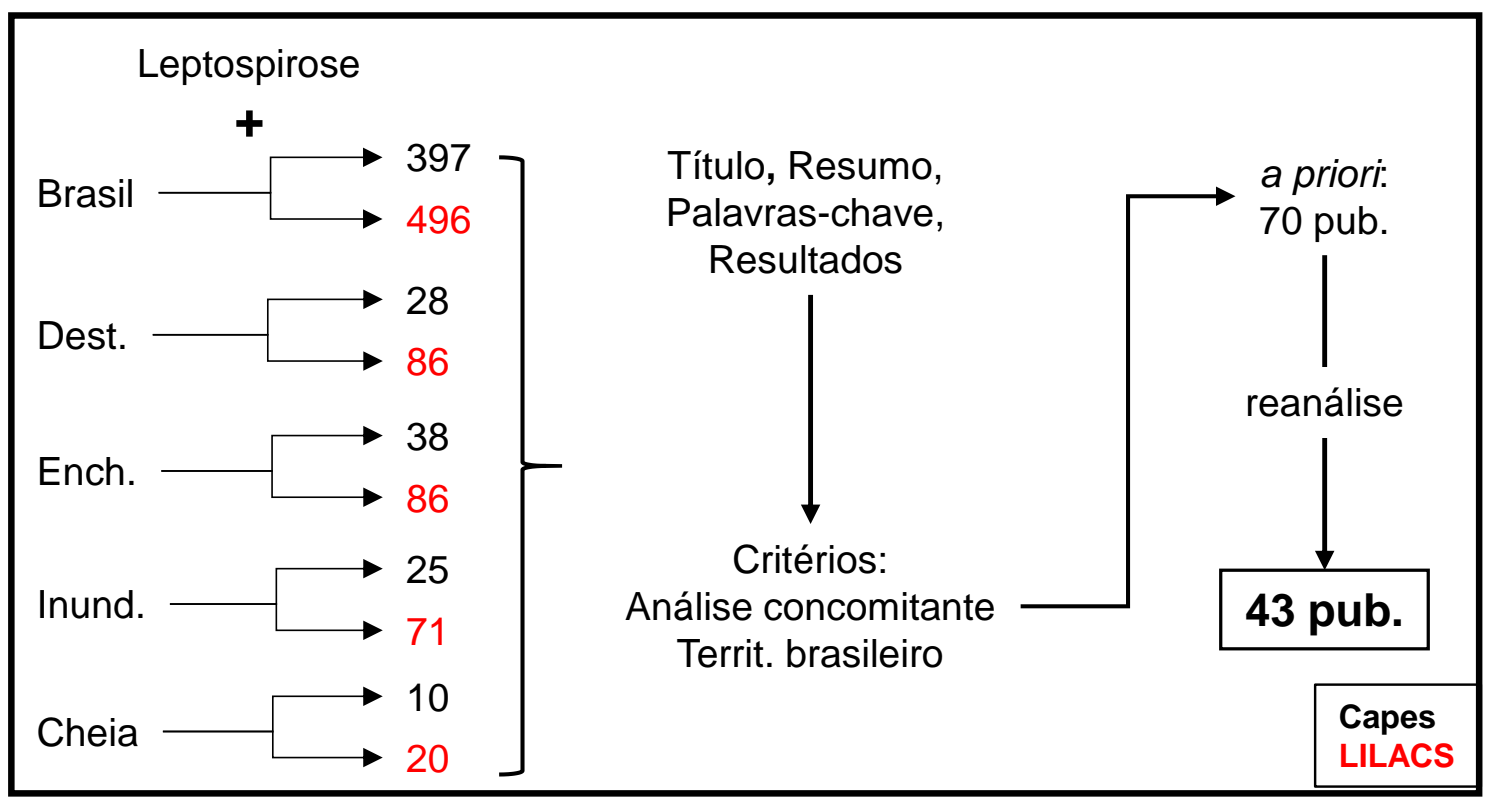

Fonte: Elaborado pelos Autores

Os artigos selecionados para análise no presente trabalho incluíram pesquisas realizadas nos estados do Rio de Janeiro (7), Bahia (3), Santa Catarina (5), Minas Gerais (1), São Paulo (6), Pernambuco (1), Pará (1), Ceará (1), Sergipe (1), Paraná (1), Rio Grande do Sul (1), Distrito Federal (1), Alagoas (1), Rondônia (1), Amazonas (1) e Brasil no geral (11). Os 11 estudos publicados de abrangência nacional demonstraram que o aumento de casos de leptospirose no Brasil possui alguns determinantes ambientais, socioeconômicos, demográficos, biológicos e climáticos que podem estar relacionados entre si (Quadro 1). Uma grande parcela desses estudos relaciona diretamente os surtos de leptospirose às inundações (PELISSARI et al., 2011; OLIVEIRA, 2012; LONDE et al., 2014; LONDE et al., 2016; MINERVINO e DUARTE, 2016). Outros fatores também estão relacionados aos surtos, como a precariedade na cobertura de saneamento básico e o crescimento demográfico desordenado (ARSKY et al., 2005; PELISSARI et al., 2011; SILVA e MOREIRA, 2013).

Quadro 1 - Onze referências pesquisadas de abrangência nacional.

\begin{tabular}{|c|c|c|}
\hline Autores & Palavras-chave & Descrição \\
\hline Arsky et al. (2005) & $\begin{array}{l}\text { Leptospirose; ambiência, PLI/área } \\
\text { (probable location of infection). }\end{array}$ & $\begin{array}{l}\text { Analisou a provável localização da } \\
\text { infecção e o ambiente de ocorrência, } \\
\text { com confirmação laboratorial, entre } \\
2001 \text { a 2003. A doença apresentou } \\
\text { mais conexão com as áreas urbanas e } \\
\text { suburbanas, sugerindo que sua } \\
\text { ocorrência está relacionada às } \\
\text { condições de vida e saneamento. }\end{array}$ \\
\hline Oliveira et al. (2009) & Leptospirose; zoonose; saúde & Sistematizou um modelo produtivo \\
\hline
\end{tabular}


PORTELA, KOBIYAMA, GOERL

\begin{tabular}{|c|c|c|}
\hline Autores & Palavras-chave & Descrição \\
\hline & pública. & $\begin{array}{l}\text { para a leptospirose, considerando os } \\
\text { determinantes sociais, demográficos, } \\
\text { biológicos e climáticos envolvidos na } \\
\text { gênese da doença e os desafios para } \\
\text { o seu controle. }\end{array}$ \\
\hline Pelissri et al. (2011) & $\begin{array}{l}\text { Leptospirose; literatura de revisão } \\
\text { (como assunto); epidemiologia. }\end{array}$ & $\begin{array}{l}\text { Revisão sistemática da produção } \\
\text { científica sobre os fatores associados } \\
\text { à leptospirose no Brasil entre } 2000 \text { e } \\
2009 \text {. A maior parte dos estudos } \\
\text { associou a ocorrência de chuva ou } \\
\text { inundações com o aumento do número } \\
\text { de casos. }\end{array}$ \\
\hline Oliveira (2012) & $\begin{array}{l}\text { Endemia; leptospirose; saúde } \\
\text { pública. }\end{array}$ & $\begin{array}{l}\text { Levantamento epidemiológico da } \\
\text { leptospirose na região Nordeste do } \\
\text { Brasil. Segundo dados observados, a } \\
\text { maior parte dos estados da região são } \\
\text { áreas consideradas endêmicas. O } \\
\text { estudo fez correlação entre períodos } \\
\text { de inundações e o aumento da } \\
\text { doença. }\end{array}$ \\
\hline Silva et al. (2013) & $\begin{array}{l}\text { Leptospirose; fatores ambientais; } \\
\text { Brasil. }\end{array}$ & $\begin{array}{l}\text { Destacou os fatores que contribuem } \\
\text { para a ocorrência da leptospirose: } \\
\text { condições socioeconômicas, hábitos } \\
\text { de vida da população, elevações } \\
\text { pluviométricas, infraestrutura e } \\
\text { moradia. }\end{array}$ \\
\hline Londe et al. (2014) & $\begin{array}{l}\text { Desastres naturais; recursos } \\
\text { hídricos; vulnerabilidade; gestão } \\
\text { de riscos. }\end{array}$ & $\begin{array}{l}\text { Abordou os aspectos dos desastres } \\
\text { relacionados à água no Brasil, } \\
\text { apontando para a importância de um } \\
\text { planejamento completo para a gestão } \\
\text { de riscos de desastres. }\end{array}$ \\
\hline Pereira (2014) & $\begin{array}{l}\text { Leptospirose; epidemiologia } \\
\text { descritiva; negligenciada; } \\
\text { doenças; saúde ambiental. }\end{array}$ & $\begin{array}{l}\text { Análise estatística da série temporal } \\
\text { de casos de leptospirose notificados } \\
\text { entre } 2008 \text { e } 2012 \text {, com base nos } \\
\text { dados do SINAN. O estudo concluiu } \\
\text { que, apesar da doença estar } \\
\text { associada a períodos de chuvas, é } \\
\text { possível que a quantidade de casos } \\
\text { seja maior se a busca continuar ativa } \\
\text { durante a estação seca. }\end{array}$ \\
\hline Siqueira et al. (2014) & $\begin{array}{l}\text { Leptospirose; saúde pública; } \\
\text { urbanização. }\end{array}$ & $\begin{array}{l}\text { Reflexão teórica sobre o processo de } \\
\text { urbanização no Brasil e a relação com } \\
\text { as doenças de veiculação hídrica, } \\
\text { como a leptospirose. Trata-se de uma } \\
\text { pesquisa bibliográfica seguindo os } \\
\text { princípios de uma pesquisa } \\
\text { exploratória. }\end{array}$ \\
\hline Clazer et al. (2015) & $\begin{array}{l}\text { Leptospira spp; ocupação; } \\
\text { roedores; trabalhadores; } \\
\text { zoonose. }\end{array}$ & $\begin{array}{l}\text { Revisão de literatura sobre diferentes } \\
\text { categorias profissional/ocupacional } \\
\text { como fator relevante para a discussão } \\
\text { de saúde pública e ocorrência de } \\
\text { doenças. }\end{array}$ \\
\hline $\begin{array}{l}\text { Minervino e Duarte } \\
(2016)\end{array}$ & $\begin{array}{l}\text { Desastres naturais; desastre } \\
\text { hidrológico; inundações; } \\
\text { avaliação de danos; base de } \\
\text { dados. }\end{array}$ & $\begin{array}{l}\text { Apresentou uma análise de dados so- } \\
\text { bre danos materiais resultantes de de- } \\
\text { sastres hidrológicos no Brasil, de } 2010 \\
\text { a } 2014 \text {, analisando dois bancos de da- } \\
\text { dos de desastre: EM-DAT (global) e } \\
\text { S2iD (nacional). A análise mostra dife- } \\
\text { renças tanto no número total de ocor- }\end{array}$ \\
\hline
\end{tabular}




\begin{tabular}{|l|l|l|}
\hline \multicolumn{1}{|c|}{ Autores } & \multicolumn{1}{|c|}{ Palavras-chave } & Descrição \\
\hline Londe et al. (2016) & $\begin{array}{l}\text { Desastres socioambientais; } \\
\text { saúde pública; doenças } \\
\text { relacionadas à água Brasil; } \\
\text { inundações. }\end{array}$ & $\begin{array}{l}\text { p̧actos danos causados quanto em rela- } \\
\text { pactos naúde pública. }\end{array}$ \\
\hline $\begin{array}{l}\text { Investigou a relação entre eventos de } \\
\text { inundação a distribuição temporal } \\
\text { dos casos de leptospirose, analisando } \\
\text { até que ponto os alertas de } \\
\text { inundaçóes podem apoiar os serviços } \\
\text { de saúde na melhor resposta a } \\
\text { ocorrência da doença. Propôs ainda } \\
\text { um monitoramento conjunto entre os } \\
\text { casos de leptospirose e a ocorrência } \\
\text { climática. }\end{array}$ \\
\hline
\end{tabular}

Fonte: Elaborado pelos Autores.

A maior parte dos 11 estudos realizados em escala nacional destacou as condições socioeconômicas como fator preponderante para o aumento do número de casos da doença. As áreas mais vulneráveis são as que dependem de investimentos em infraestrutura e planejamento urbano (OLIVEIRA, 2012; SILVA e MOREIRA, 2013; LONDE et al., 2016; MINERVINO e DUARTE, 2016). Ko et al. (1999), Coelho et al. (2012) e Greice et al. (2014) demonstraram que a incidência da doença é menor em países desenvolvidos. Em países em desenvolvimento e tropicais, onde a leptospirose é emergente ou altamente prevalente, os surtos da doença vêm aumentando, principalmente em áreas urbanas com precárias condições socioeconômicas.

Os estudos em diferentes regiões relacionaram diversos fatores ao risco de leptospirose e sua ocorrência em distintas realidades do país (Quadro 2). No Brasil, as maiores epidemias de leptospirose ocorrem, geralmente, em grandes centros urbanos como Rio de Janeiro, São Paulo, Belo Horizonte, Salvador e Recife. Observa-se que dos 43 trabalhos apresentados, 27 (62\%) foram publicados após 2012, data dos eventos hidrológicos extremos ocorridos no Vale do Itajaí/SC em 2008 (FRANK e SEVEGNANI, 2009) e no Rio de Janeiro em 2011 (FREITAS et al., 2012).

Quadro 2 - Referências pesquisadas por regiões/estados brasileiros.

\begin{tabular}{|c|c|c|}
\hline Região (estados) & Autores & Descrição dos estudos \\
\hline $\begin{array}{l}\text { REGIÃO SUL } \\
\text { (SC/PR/RS) }\end{array}$ & $\begin{array}{l}\text { De Paula (2005) } \\
\text { Andrade (2009) } \\
\text { Santos et al. (2012) } \\
\text { Silva (2013) } \\
\text { Londe et al. (2015) } \\
\text { Schneider (2015) }\end{array}$ & $\begin{array}{l}\text { Na Região Sul, foram desenvolvidos estudos em } \\
\text { Blumenau (ANDRADE, 2009), Itajaí (SANTOS et } \\
\text { al., 2012), São José (SILVA, 2013) e Chapecó } \\
\text { (BUSATO et al., 2017), em Santa Catarina; } \\
\text { Curitiba (DE PAULA, 2005), no Paraná; e sobre o } \\
\text { Estado do Rio Grande do Sul (SCHNEIDER, } \\
\text { 2015). Há ainda um estudo comparando as } \\
\text { inundações nos Estados de SC e PE (LONDE et } \\
\text { al., 2015). Os autores fazem uma análise }\end{array}$ \\
\hline
\end{tabular}




\begin{tabular}{|c|c|c|}
\hline Região (estados) & Autores & Descrição dos estudos \\
\hline & Busato et al. (2017) & $\begin{array}{l}\text { temporal das inundações com o aumento dos } \\
\text { casos (DE PAULA, 2005; ANDRADE, 2009; } \\
\text { SANTOS et al., 2012; SILVA, 2013; LONDE et } \\
\text { al., 2015; SCHNEIDER, 2015). Dois estudos são } \\
\text { de caráter exploratório descritivo-transversal, } \\
\text { destacando as infecções ocorridas } \\
\text { principalmente durante a exposição ocupacional } \\
\text { (SCHNEIDER, 2015; BUSATO et al., 2017). De } \\
\text { maneira geral, os trabalhos relacionam a } \\
\text { incidência de leptospirose às condições } \\
\text { socioeconômicas em populações mais } \\
\text { suscetíveis (DE PAULA, 2005; ANDRADE, 2009; } \\
\text { SANTOS et al., 2012; SILVA, 2013; LONDE et } \\
\text { al., 2015; SCHNEIDER, 2015; BUSATO et al., } \\
\text { lo17). Foi indicada a falta de saneamento básico } \\
\text { como um fator agravante em períodos de } \\
\text { inundações atingindo as populações mais } \\
\text { suscetíveis (DE PAULA, 2005; ANDRADE, 2009; } \\
\text { SANTOS et al., 2012; SILVA, 2013; LONDE et } \\
\text { al., 2015; BUSATO et al., 2017). Por fim, há } \\
\text { estudos que concluem que as populações rurais } \\
\text { possuem mais casos de leptospirose do que nas } \\
\text { áreas urbanas (SCHNEIDER, 2015; BUSATO et } \\
\text { al., 2017). }\end{array}$ \\
\hline $\begin{array}{l}\text { REGIÃO SUDESTE } \\
\text { (SP/RJ/MG) }\end{array}$ & $\begin{array}{l}\text { Souza (1986) } \\
\text { Barcellos e Sabroza (2001) } \\
\text { Confalonieri (2003) } \\
\text { Tassinari et al. (2004) } \\
\text { Soares et al. (2010) } \\
\text { Belchior e Azevedo (2012) } \\
\text { Coelho e Massad (2012) } \\
\text { Oliveira et al. (2012) } \\
\text { Greice et al. (2014) } \\
\text { Guimarães et al. (2014) } \\
\text { Pereira (2014) } \\
\text { Dutra et al. (2015) } \\
\text { Aleixo e Neto (2016) } \\
\text { Chaiblich et al. (2017) }\end{array}$ & 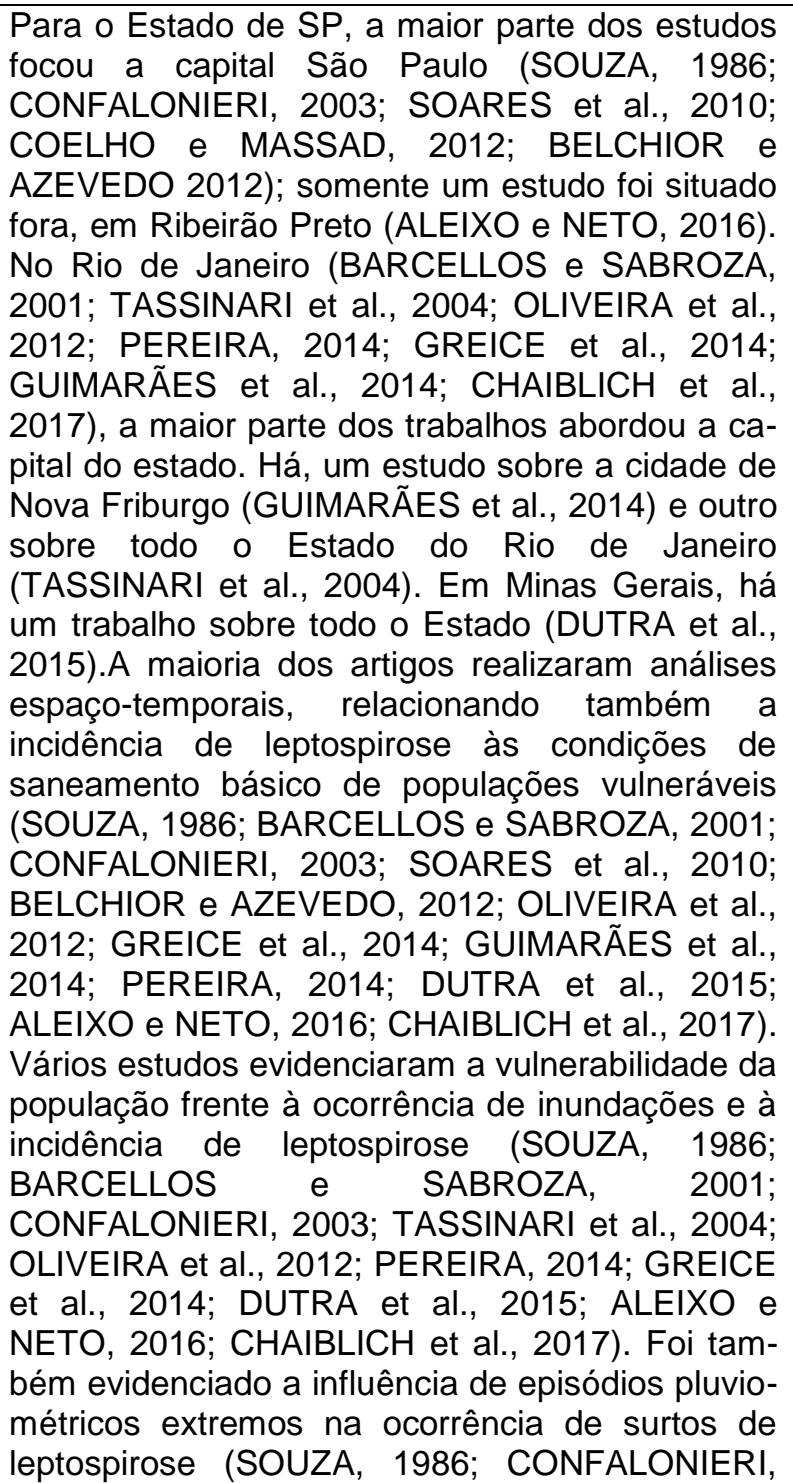 \\
\hline
\end{tabular}




\begin{tabular}{|c|c|c|}
\hline Região (estados) & Autores & Descrição dos estudos \\
\hline & & $\begin{array}{l}\text { 2003; TASSINARI et al., 2004; GREICE et al., } \\
\text { 2014; SOARES et al., 2010; BELCHIOR e } \\
\text { AZEVEDO, 2012; OLIVEIRA et al., 2012; } \\
\text { GUIMARÃES et al., 2014; DUTRA et al., 2015; } \\
\text { CHAIBLICH et al., 2017). Dois estudos apresen- } \\
\text { taram a importância da atuação da Vigilância em } \\
\text { Saúde na prevenção e resposta frente à ocorrên- } \\
\text { cia de casos de leptospirose (TASSINARI et al., } \\
\text { 2004; CHAIBLICH et al., 2017). Um estudo de- } \\
\text { monstrou o custo social dos casos de leptospi- } \\
\text { rose notificados em } 2008 \text { no Brasil. A pesquisa } \\
\text { desenvolvida sobre Ribeirão Preto apontou que, } \\
\text { apesar da ocorrência da doença aumentar no pe- } \\
\text { ríodo chuvoso, as inundações foram apontadas } \\
\text { como a segunda principal forma de transmissão } \\
\text { da doença (ALEIXO e NETO, 2016). }\end{array}$ \\
\hline $\begin{array}{l}\text { REGIÃO NORDESTE } \\
(\mathrm{PE} / \mathrm{CE} / \mathrm{SE} / \mathrm{AL} / \mathrm{BA})\end{array}$ & $\begin{array}{l}\text { Ko et al. (1999) } \\
\text { Costa et al. (2001) } \\
\text { Reis et al. (2008) } \\
\text { Magalhães et al. (2009) } \\
\text { Melo et al. (2011) } \\
\text { Vasconcelos et al. (2012) } \\
\text { Freire et al. (2014) }\end{array}$ & 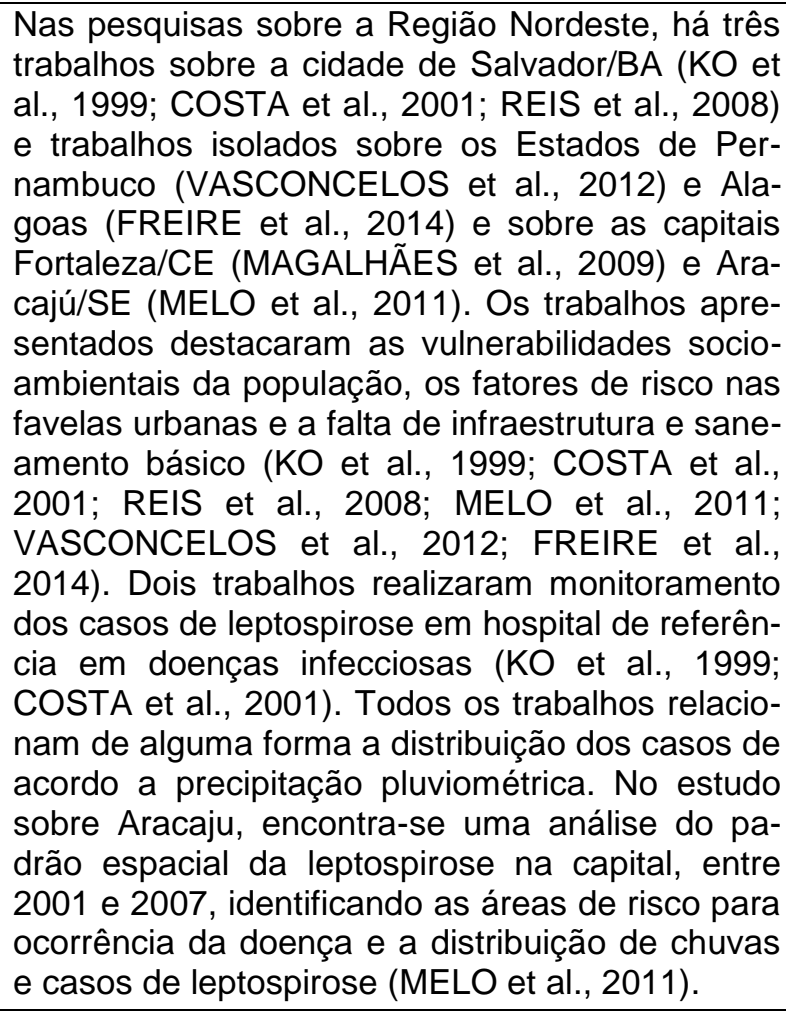 \\
\hline $\begin{array}{l}\text { REGIÃO NORTE } \\
\text { (RO/PA/AM) }\end{array}$ & $\begin{array}{l}\text { Franca e Mendonça (2015) } \\
\text { Gonçalves et al. (2016) } \\
\text { Souza e Nascimento (2017) }\end{array}$ & $\begin{array}{l}\text { Os estudos da Região Norte apresentam } \\
\text { trabalhos sobre Porto Velho/RO (FRANCA e } \\
\text { MENDONÇA, 2015), Belém/PA (GONÇALVES et } \\
\text { al., 2016) e sobre o Estado do Amazonas } \\
\text { (SOUZA e NASCIMENTO, 2017). Essa região } \\
\text { apresenta algumas peculiaridades devido às } \\
\text { cheias que ocorrem sazonalmente. Todos os } \\
\text { estudos relataram fatores de rescos } \\
\text { socioambientais associados à ocorrência de } \\
\text { leptospirose (FRANCA e MENDONÇA, 2015; } \\
\text { GONÇALVES et al., 2016; SOUZA e } \\
\text { NASCIMENTO, 2017). Os trabalhos também } \\
\text { apresentaram análises temporais, relacionando o } \\
\text { aumento da incidência de leptospirose à } \\
\text { ocorrência de inundaçôes (FRANCA e } \\
\text { MENDONÇA, 2015; GONÇALVES et al., 2016; } \\
\text { SOUZA e NASCIMENTO, 2017). Foi realizado } \\
\text { um estudo transversal e descritivo sobre } \\
\text { correlações espaciais de fatores de risco } \\
\text { socioambientais com a leptospirose em Belém, }\end{array}$ \\
\hline
\end{tabular}




\begin{tabular}{|c|c|c|}
\hline Região (estados) & Autores & Descrição dos estudos \\
\hline & & $\begin{array}{l}\text { entre } 2007 \text { e } 2013 \text { (GONÇALVES et al., 2016). } \\
\text { No estudo sobre o Estado de Amazonas, foi } \\
\text { identificado um padrão temporal de } \\
\text { comportamento de leptospirose, doenças } \\
\text { diarreicas agudas e outros agravos, por meio da } \\
\text { análise de dados por quadriênios obtidos no } \\
\text { Sistema Nacional de Agravos Notificados } \\
\text { (SINAN) e Sistema de Vigilância Epidemiológica } \\
\text { (SIVEP Malária) (SOUZA e NASCIMENTO, } \\
\text { 2017). }\end{array}$ \\
\hline $\begin{array}{l}\text { REGIÃO CENTRO- } \\
\text { OESTE } \\
\text { (DF) }\end{array}$ & Santos (2016) & $\begin{array}{l}\text { O estudo demostrou que a leptospirose apre- } \\
\text { senta um perfil urbano em área com acesso da } \\
\text { população à rede de esgoto, água tratada e ser- } \\
\text { viço de coleta de lixo. Ocorreu com maior fre- } \\
\text { quência na estação chuvosa e apresentou forte } \\
\text { associação com roedores sinantrópicos } \\
\text { (SANTOS, 2016). }\end{array}$ \\
\hline
\end{tabular}

Fonte: Elaborado pelos Autores.

O Rio de Janeiro se destaca entre os trabalhos pesquisados no Brasil, concentrando o maior número de publicações. Dois estudos demonstram que este estado tem uma das maiores incidências de leptospirose do Brasil: Chaiblich et al. (2017), que analisaram dados entre 1985 e 2005; Greice et al. (2014), que analisaram dados entre 1996 e 1999. Em áreas urbanas densamente povoadas, característica encontrada na capital fluminense, ocorre um grande número de casos de leptospirose em locais com acumulação de lixo a céu aberto, já que os riscos decorrentes do acúmulo desses resíduos, a infestação de roedores e a contaminação por bactérias são fatores determinantes para a sua incidência. Além dos fatores listados, a presença da Fundação Oswaldo Cruz (Fiocruz) pode contribuir para que o Rio de Janeiro apresente o maior número de estudos.

Tassinari et al. (2004) e Andrade (2009) enfatizaram que a água exerce um papel importante na transmissão de leptospirose em períodos de inundação, em que grandes contingentes de indivíduos estão suscetíveis à doença. Estes estudos ressaltam, ainda, outros fatores como características do solo, tempo de escoamento e período de exposição das águas que contribuem para o aparecimento de surtos.

Londe et al. (2016) relacionaram os surtos de leptospirose no Brasil à ocorrência de inundações em alguns municípios brasileiros. Os autores abordaram questões relacionadas a monitoramento conjunto entre os casos de leptospirose e a ocorrência climática e concluíram que os dados de inundação também podem ser úteis para a análise de surtos tanto quanto os dados de precipitações.

Por outro lado, conforme Magalhães et al. (2009), não se pode afirmar que a contaminação ocorre somente pelos altos índices de precipitação. Em ambientes 
propícios, por exemplo, há existência permanente de roedores e outros hospedeiros intermediários com potencial de transmissão da doença também em períodos não chuvosos.

Além da quantidade de precipitação, fator de influência e relevância para o aumento dos casos, outros múltiplos fatores contribuem para o seu aparecimento. Ko et al. (1999) e Schneider et al. (2015) citaram que a infraestrutura sanitária precária, conglomerados urbanos em situação de vulnerabilidade socioeconômica, baixa escolaridade, atividades laborais, infestação de roedores e acúmulo de lama e resíduos podem contribuir para o aparecimento de surtos.

As questões relacionadas à urbanização desordenada foram destacadas pela maior parte das publicações. Tassinari et al. (2004), Oliveira (2009), Greice et al. (2014), e Chaiblich et al. (2017) indicaram que atualmente a leptospirose é uma doença de áreas urbanas, principalmente em locais com crescimento desordenado e com precariedade de saneamento básico.

As análises de São Paulo (SOARES et al., 2010), Vale do Itajaí/SC (SANTOS et al., 2012) e Belém/PA (GONÇALVES et al., 2016) demonstraram que cerca de metade dos casos de leptospirose foi por infecção no próprio domicílio. Nos períodos de inundações, a água invade as casas próximas aos rios e córregos, expondo os moradores ao risco do contato com a água contaminada pela urina dos roedores. Estes autores relacionaram a doença à vulnerabilidade socioeconômica em conjunto com altos índices pluviométricos.

Souza (1986), em um dos estudos pioneiros em São Paulo, demonstrou que dos 200 casos de leptospirose analisados, 53,6\% estavam relacionados às inundações, com maior frequência no verão. As inundações continuam sendo um risco de infecção clínica ou subclínica de leptospirose humana, gerando consequências para a população que habita áreas de vulnerabilidade socioambiental (COELHO e MASSAD, 2012).

Ko et al. (1999), Costa et al. 2001) e Reis et al. (2008) demonstraram que os indivíduos com maior risco de leptospirose são os habitantes de assentamentos irregulares nas periferias da cidade e com carência de saneamento básico. Esses autores demonstraram que a leptospirose está diretamente relacionada a baixos níveis socioeconômicos e que o aumento da precipitação precede surtos epidêmicos.

Melo et al. (2011), por meio de levantamento realizado pela Vigilância Epidemiológica de Sergipe entre 2001 e 2007, constataram que o estado teve um 
total de 329 casos; dos quais 45 resultaram em óbito. Em Aracaju, no mesmo período de análise, foram registrados 205 casos e 28 óbitos.

Melo et al. (2011) Silva e Moreira (2013), e Pereira (2014) enfatizaram a importância dos profissionais de saúde investigarem a incidência de leptospirose não somente nos períodos chuvosos, mas também nos períodos de seca. Segundo estes autores, esperar que os casos da doença somente ocorram nos períodos de inundação, além de dificultar o diagnóstico e tratamento adequados, contribui para a subnotificação de casos.

Melo et al. (2011) observaram que em Aracaju a leptospirose apresenta o mesmo padrão de distribuição espacial, tanto nos períodos de chuva como nos períodos de seca, coincidindo espacialmente com as áreas mais suscetíveis a ocorrência da doença. Pode-se observar que mesmo nos períodos de seca ocorre a transmissão da doença devido a fatores socioeconômicos e situações precárias de saneamento.

Realizando a pesquisa em Alagoas, Freire et al. (2014) destacaram que a população mais vulnerável acaba ocupando as áreas mais próximas das margens de rios e córregos, estando consequentemente mais propensas a doenças em épocas de cheias. No Amazonas, Souza e Nascimento (2017) levantaram a questão das áreas de risco, cuja população ribeirinha é a mais atingida durante os períodos de inundação, com perdas na produção agrícola, em que as águas invadem as plantações, trazendo sujeiras e impurezas e provocando doenças de veiculação hídrica.

Gonçalves et al. (2016), ao analisarem os casos ocorridos em Belém-PA, observaram que $69 \%$ das notificações foram de pessoas do sexo masculino. Belchior e Azevedo (2012) citaram que a maioria das pessoas acometidas pela doença são homens entre 20 e 49 anos, ou seja, em idade produtiva.

Souza (1986), De Paula (2005), Aleixo e Neto (2010), Belchior e Azevedo (2012) e Dutra et al. (2015) indicaram que a incidência de leptospirose está intimamente relacionada ao período chuvoso do verão, pois, com o aumento do volume de água, a leptospira é transportada rapidamente pelo contato com as águas de inundações. Além disso, este período de clima quente e úmido faz com que as pessoas tenham maior contato com a água de rios, córregos e lagos, em atividades de recreação e lazer.

Pelissari et al. (2011) observaram que no Brasil a doença tem distribuição endêmica, ocorrendo durante todo o ano e não somente no verão. Contudo, um 
aumento de casos registrados ocorre durante o período sazonal das precipitações nas principais metrópoles do país. Os autores ainda reiteraram que os resultados obtidos pela maioria dos estudos de outros pesquisadores associam as condições socioeconômicas das comunidades e a precariedade do saneamento básico à ocorrência de surtos da doença.

Schneider et al. (2015) enfatizaram que a leptospirose é um problema de saúde pública para o Rio Grande do Sul, com uma média de 428 casos/ano. A incidência real é provavelmente muito maior, particularmente em populações mais vulneráveis, porque a leptospirose é comumente diagnosticada erroneamente e não declarada. Os resultados desse estudo demonstram que as populações rurais do estado têm aproximadamente oito vezes maior risco de contrair leptospirose do que suas contrapartes urbanas, o que o diferencia dos demais estudos realizados nessa revisão. Estes autores apontaram ainda que no interior do estado os riscos estão relacionados às atividades ocupacionais, como nas lavouras de tabaco, por exemplo. Busato et al. (2017) corroboraram isso, apontando que cerca de $28 \%$ dos casos notificados no Brasil relacionam-se às áreas rurais atingiram os trabalhadores do setor agrícola.

A revisão bibliográfica listada apontou que, além das variáveis climáticas e do crescimento urbano desordenado, a vulnerabilidade socioeconômica e a deficiência do saneamento básico somado ao acúmulo de lixo localizados nas áreas mais pobres são fatores preponderantes para o surgimento do surto da doença.

Com base nos dados disponíveis no DATASUS, os dez estados com maior frequência de casos e óbitos de leptospiroses no período de 2000 a 2017 foram elencados na Tabela 2. No Estado do Rio de Janeiro, foi registrado $6 \%$ de todos os casos confirmados de leptospirose e $13 \%$ de todos os óbitos relacionados à doença no Brasil.

Tabela 2 - Ranking dos 10 primeiros estados em relação ao número de casos, óbitos e publicações entre 2000 e 2017.

\begin{tabular}{|c|c|c|c|c|c|c|c|c|}
\hline \multirow[b]{2}{*}{ Ranking } & \multirow[b]{2}{*}{ Estado } & \multicolumn{2}{|c|}{ Casos } & \multicolumn{2}{|c|}{ Óbitos } & \multirow{2}{*}{$\begin{array}{l}\text { Óbitos/ } \\
\text { Casos } \\
(\%)\end{array}$} & \multicolumn{2}{|c|}{ Public. } \\
\hline & & $\begin{array}{c}\text { Número } \\
\text { total }\end{array}$ & $\%$ & $\begin{array}{c}\text { Número } \\
\text { total }\end{array}$ & $\%$ & & $\begin{array}{l}\text { Número } \\
\text { total }\end{array}$ & $\%$ \\
\hline $1^{\circ}$ & São Paulo & 13.583 & 20,43 & 1.661 & 25,88 & 12,23 & 6 & 18 \\
\hline $2^{\circ}$ & R. Grande do Sul & 9.038 & 13,59 & 526 & 8,20 & 5,82 & 1 & 3 \\
\hline $3^{\circ}$ & Santa Catarina & 7.245 & 10,90 & 283 & 4,41 & 3,91 & 5 & 15 \\
\hline $4^{\circ}$ & Paraná & 5.098 & 7,67 & 581 & 9,05 & 11,40 & 1 & 3 \\
\hline $5^{\circ}$ & Pernambuco & 4.882 & 7,34 & 607 & 9,46 & 12,13 & 2 & 6 \\
\hline $6^{\circ}$ & Rio de Janeiro & 4.487 & 6,75 & 841 & 13,11 & 18,74 & 7 & 21 \\
\hline
\end{tabular}




\begin{tabular}{l|lcc|cc|c|cc}
$7^{\circ}$ & Acre & 4.245 & 6,38 & 48 & 0,75 & 1,13 & 0 & 0 \\
$8^{\circ}$ & Espírito Santo & 2.823 & 4,25 & 138 & 2,15 & 4,89 & 0 & 0 \\
$9^{\circ}$ & Pará & 2.432 & 3,66 & 306 & 4,77 & 12,58 & 1 & 3 \\
$10^{\circ}$ & Bahia & 2.336 & 3,51 & 335 & 5,22 & 14,34 & 3 & 9 \\
\hline & Total & $\mathbf{5 6 . 1 6 9}$ & $\mathbf{8 4 , 4 6}$ & $\mathbf{5 . 3 2 6}$ & $\mathbf{8 2 , 9 9}$ & $\mathbf{9 , 4 8}$ & $\mathbf{2 6}$ & $\mathbf{7 9}$ \\
& Total do Brasil & $\mathbf{6 6 . 4 9 6}$ & $\mathbf{1 0 0}$ & $\mathbf{6 . 4 1 7}$ & $\mathbf{1 0 0}$ & $\mathbf{9 , 6 5}$ & $\mathbf{3 3}$ & $\mathbf{1 0 0}$ \\
\hline
\end{tabular}

Fonte: Elaborado pelos Autores

Santa Catarina foi objeto de estudo de cinco trabalho que demonstram que os fatores climáticos e os desastres hidrológicos ocorridos nos últimos anos podem estar relacionados ao aumento de casos. O Acre e o Espírito Santo não possuem nenhum estudo selecionado nesse levantamento bibliográfico, apesar do número de casos e óbitos registrados.

Entre os 10 estados listados na Tabela 2, o Acre e o Espirito Santo apresentam a primeira e a terceira menor taxa de mortalidade entre os casos registrados, além disso, são os únicos que não possuem publicações. São Paulo e Rio de Janeiro apresentam a primeira e segunda maior taxa de mortalidade. Nota-se que a relação entre casos e óbitos nos 10 primeiros estados é similar àquela geral do Brasil. Destaca-se o Rio de Janeiro, que mesmo não apresentando o maior valor em total de registros, apresentou a maior relação óbitos/casos. Utilizando os dados do DATASUS, o Gráfico 1 mostra uma correlação positiva entre os números de óbitos e casos de todos os estados brasileiros em conjunto, sendo que o elevado valor de $R^{2}(0,76)$ implica uma correlação forte entre os locais de maior ocorrência e maiores óbitos. 
Gráfico 1 - Correlação entre óbitos e casos para todos os estados brasileiros $(p<0,0001)$.

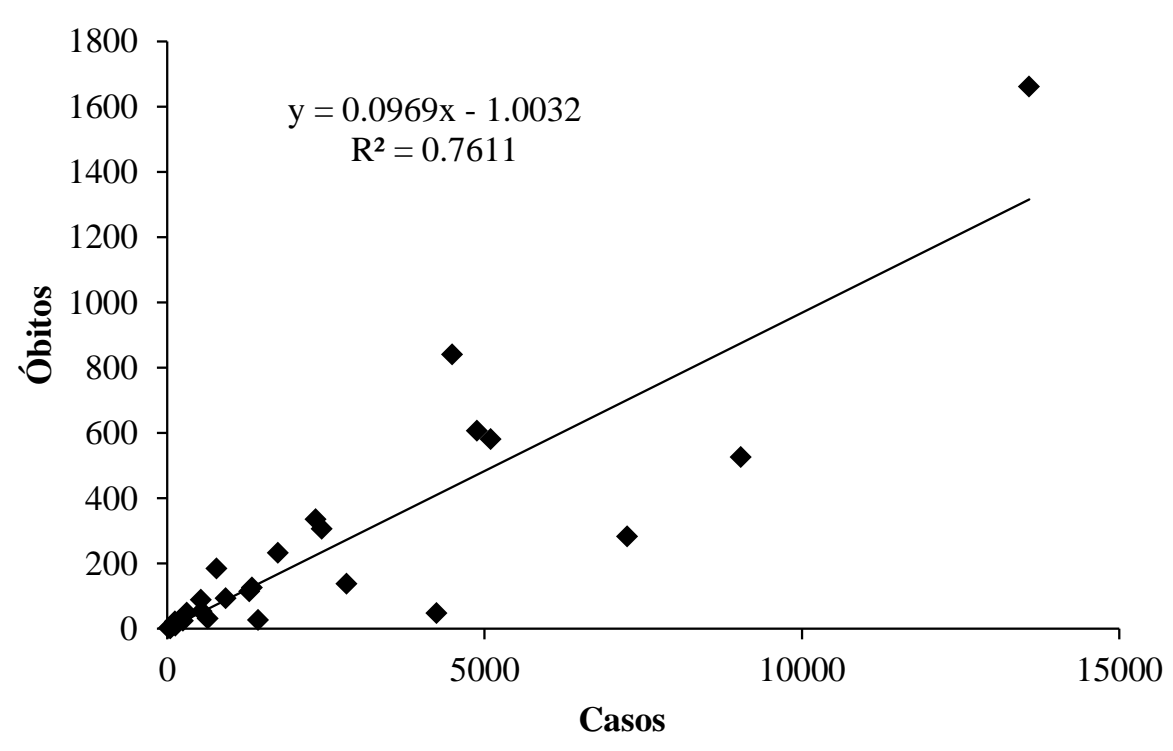

Fonte: Elaborado pelos Autores

Com base dos dados do DATASUS, as distribuições estaduais de casos, óbitos e publicações sobre leptospirose no período de 2000 a 2017 foram elaboradas (Figura 2). Os estados de São Paulo, Rio Grande do Sul e Pernambuco, por terem elevado crescimento demográfico, grandes áreas periféricas e altos índices pluviométricos, figuram entre os estados com maiores números de óbitos e casos.

Figura 2 - Mapas do número de casos, óbitos e publicações sobre leptospirose entre 2000 e 2017.

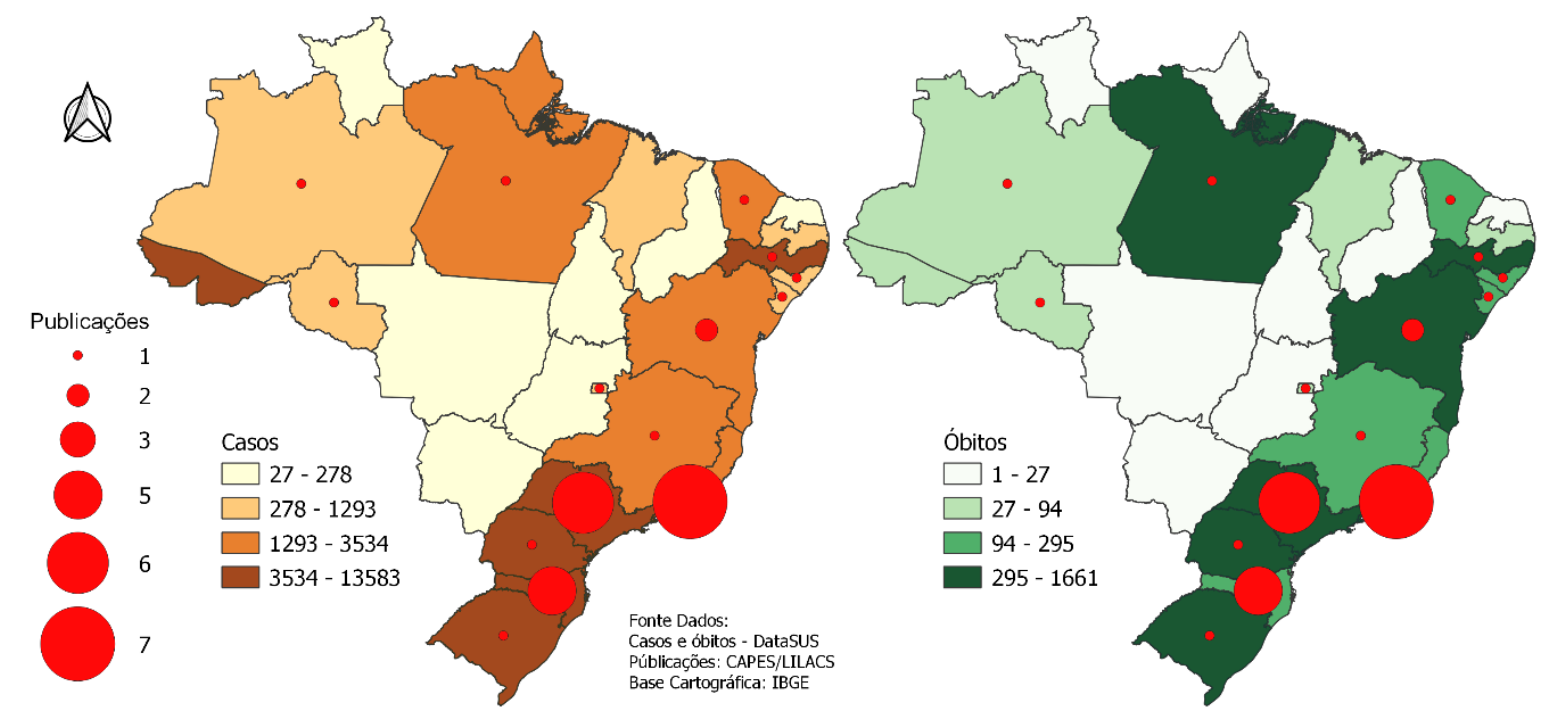

Fonte: Elaborado pelos Autores. 
Em São Paulo, nota-se uma quantidade relevante de pesquisas - tanto devido ao grande número de ocorrência e óbito da doença, como devido ao fato de a capital ser uma das maiores metrópoles do mundo, com importantes centros de pesquisas e universidades. As áreas localizadas próximas do litoral brasileiro concentram o maior número de trabalhos publicados e registram o maior número de casos confirmados e de óbitos. A escassez de trabalhos científicos no Centro-Oeste, Norte e Nordeste, com enfoque em leptospirose, demonstra que é necessário a comunidade científica avançar mais nos estudos sobre o assunto em todas as regiões do Brasil.

Observa-se no Gráfico 2 que existe uma tendência do aumento no número de publicações a partir de 2008, com picos mais relevantes nos anos de 2012 e 2014. Este aumento de pesquisas sobre a temática pode estar relacionado a alguns fatos: (i) a ocorrência de dois grandes eventos de desastres hidrológicos nesse período (Santa Catarina em 2008 e Rio de Janeiro em 2011); (ii) publicação da Portaria do Ministério da Saúde (n.5 anexo II de 2006) sobre a obrigatoriedade de notificar toda a emergência em saúde pública, com consequente aumento no número de notificações no SINAN; (iii) a criação e implantação da Unidade de Resposta Rápida (URR) nos estados; (iv) a criação do Regulamento Sanitário Internacional em 2005; (v) a estruturação da Vigilância em Saúde Ambiental em níveis nacional e estadual, a partir de 2004; e (vi) o estabelecimento de rede de monitoramento hidrometeorológico. A maior disponibilidade de dados proporcionou a realização de uma maior quantidade de estudos, demonstrando a importância da criação e manutenção de banco de dados, bem com a sua publicidade.

Nota-se também no Gráfico 2 as correlações entre casos e publicação e entre óbitos e publicações. Observa-se que houve um aumento no número de casos e óbitos, e o número de trabalhos pesquisados acompanhou este aumento. O aprimoramento do acesso à bancos de dados sobre desastres e notificação de doenças, por meio de ferramentas e sistemas on-line, permitiu uma melhora no cruzamento dessas informações, estimulando um número crescente de pesquisas sobre o assunto. O surgimento, nos últimos anos, de cursos especializados sobre gestão de riscos de desastres, também pode ter incitado a realização de estudos, levando a observações sobre as áreas mais atingidas e as causas do aumento no número de casos e óbitos no Brasil. $O$ valor de $R^{2}$ no caso de óbito foi maior do que o de casos, o que implica que a ocorrência desses óbitos, sensibiliza ainda mais a comunidade técnico-científica. 
Gráfico 2 - Tendência temporal com as publicações sobre leptospirose de 2000 a 2017 e relação entre casos e óbitos e publicações no Brasil: (a, c) casos $(p<0,05)$; (b, d) óbitos ( $p$ $<0,005)$.

a)
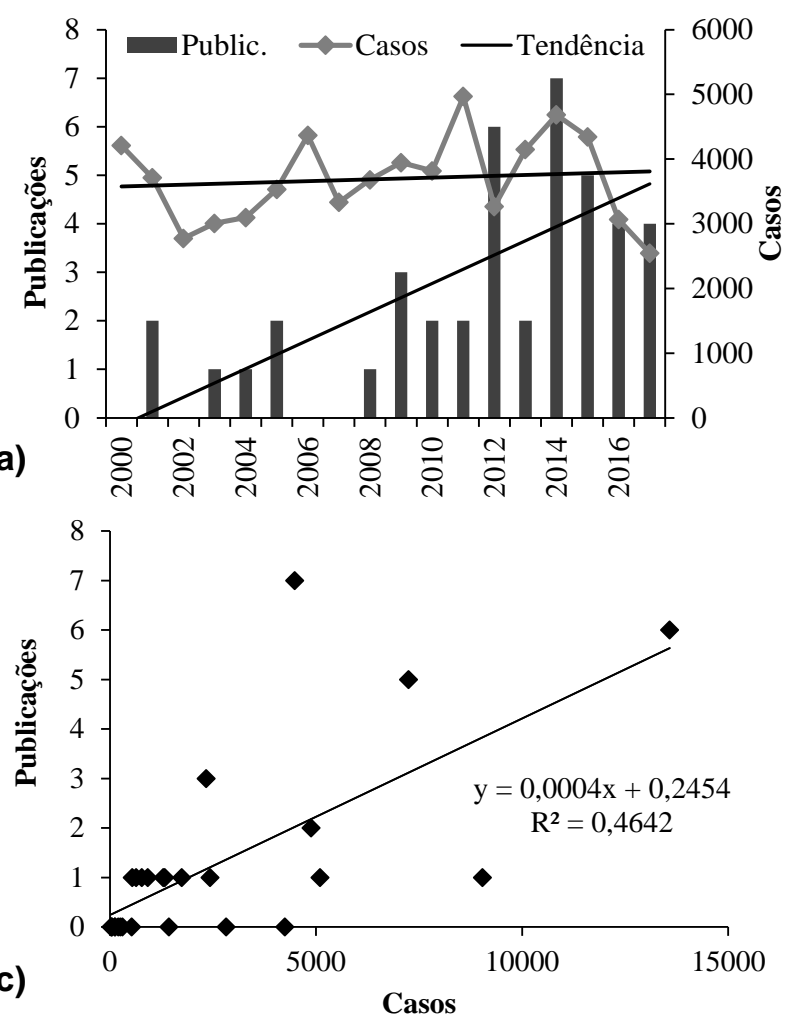

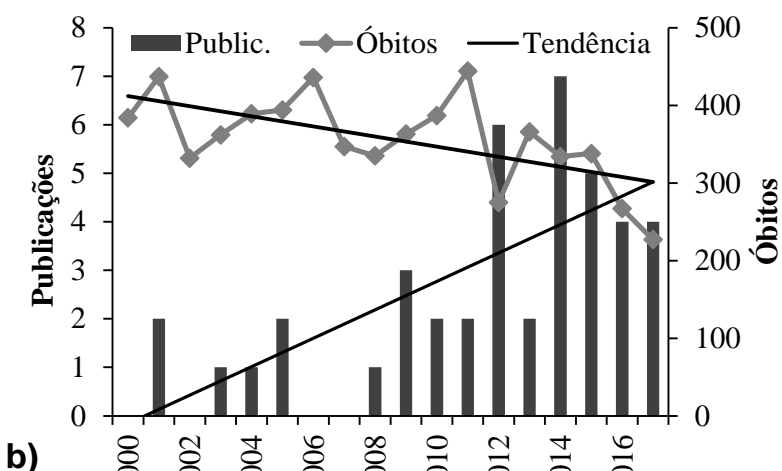

b)

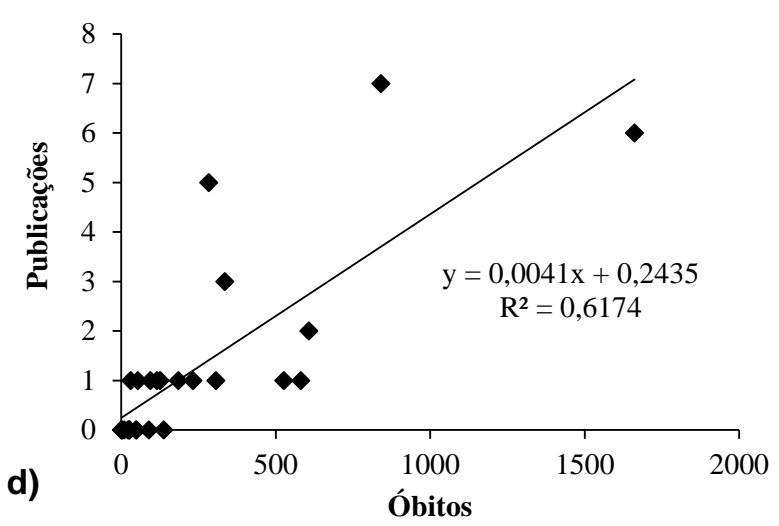

Fonte: Elaborado pelos Autores.

Existem diferentes fatores socioeconômicos que elevam o número de óbitos em alguns estados em comparação com outros, como vulnerabilidade das populações atingidas pelos desastres ou pela doença; qualidade de preparação dos órgãos oficiais, educação ambiental, políticas públicas, predisposição a ocorrência da doença, entre outros. Entretanto, pode-se dizer que, de maneira geral, em estados com melhor infraestrutura/preparação e com um elevado número de casos, o número de óbitos em decorrência da leptospirose tende a ser reduzido. Esse tipo de análise fica mais evidente com o cruzamento e o acesso dessas informações para os pesquisadores, possibilitando aos gestores uma relevante contribuição para mitigar o número de casos e óbitos pela doença no Brasil.

\section{Considerações Finais}

Os artigos analisados no presente trabalho demonstraram que a ocorrência da leptospirose nas áreas urbanas pode estar relacionada às precárias condições socioambientais da população. Observou-se em várias publicações que a incidência de leptospirose e sua relação com os períodos de eventos hidrológicos extremos 
ocorrem não somente nos períodos de verão, mas também em outras estações do ano.

A maior parte dos trabalhos demonstrou uma relação positiva entre a ocorrência de inundações e o aumento do número de casos. Porém, poucos trabalhos exploraram a periodicidade das inundações em escala local, deixando de utilizar tais dados como ferramenta de análise e prevenção. Estudos futuros sobre esta questão poderão servir de base para o desenvolvimento e o aprimoramento dos sistemas de monitoramento e alertas no Brasil. Informações sobre o comportamento epidemiológico da doença, tanto em animais como em humanos, embasariam a implantação de políticas de saúde pública e ambiental.

Os contrastes socioambientais presentes nos grandes centros forçam os moradores desfavorecidos a ocuparem áreas sujeitas a inundações, cujos problemas de saneamento, má infraestrutura de drenagem urbana e coleta de lixo constituem elevado risco à doença, favorecendo a proliferação de roedores nestas áreas.

O desenvolvimento de políticas integradas de prevenção em saúde pública e saneamento básico (DULAC e KOBIYAMA, 2017) é um importante instrumento de controle e vigilância ambiental em saúde. A gestão integrada pode reduzir significativamente a incidência da doença e seus impactos socioeconômicos, inclusive incidindo nos números de morbimortalidade. Os aspectos intersetorial e interdisciplinar na gestão dos desastres hidrológicos vêm estimulando os gestores da saúde a terem um olhar mais amplo sobre o assunto, formulando políticas públicas e desenvolvendo ações mais enfáticas na prevenção e na resposta.

Pela temporalidade do período pesquisado, constata-se que os problemas relacionados à incidência de leptospirose ocorrem há décadas. Muitos dados podem e devem ser aprimorados para comprovar a relação entre o aumento dos casos da doença e a incidência de precipitações e inundações, principalmente nos centros urbanos. As inundações se tornariam, assim, um fator desencadeador indireto, trazendo à tona vulnerabilidades urbanas como falta de saneamento e planejamento adequados. Caso as políticas públicas e de gestão de risco sejam efetivas, esperase no futuro uma correlação negativa entre com o número de publicações e o número de casos e óbitos. Em outras palavras, espera-se que o aumento do número de publicações tende a diminuir o número de casos e óbitos. 


\section{REFERÊNCIAS}

ALDERMAN, K.; TURNER, L.R.; TONG, S. Floods and human health: a systematic review. Environment International, v.47, p.37-47, 2012.

ALEIXO, N.C.R.; Neto, J.L.S. Eventos pluviométricos extremos e saúde: perspectivas de interação pelos casos de leptospirose em ambiente urbano. Hygeia - Revista Brasileira de Geografia Médica e Saúde, v.6, n.11, p.118-132, 2010.

ANDRADE, A.S.P. A relação entre a incidência de doenças de veiculação hídrica e a inundação em 2008 na cidade de Blumenau/SC. 2009. Trabalho de conclusão de curso (Graduação em Engenharia Sanitária e Ambiental), Universidade Federal de Santa Catarina, Florianópolis, 2009.

ARSKY, M.L.N.S.; OLIVEIRA, W.K.; OLIVEIRA, R.C.; ARRUDA, A.S. Probable areas of infection and ambience of occurrence of human leptospirosis in Brazil (2001-2003). Revista Cubana de Medicina Tropical, v.57, n.1, p.59-60, 2005.

BARCELLOS, C.; SABROZA, P.C. The place behind the case: leptospirosis risks and associated environmental conditions in a flood-related outbreak in Rio de Janeiro. Cadernos de Saúde Pública, v.17, n.Supl., p.59-67, 2001.

BELCHIOR, N.K.; AZEVEDO, T.S. Distribuição da leptospirose nos municípios do Estado de São Paulo no período de 2008 a 2010. Hygeia - Revista Brasileira de Geografia Médica e da Saúde, v.8, n.14, p.39-52, 2012.

BUSATO, M.A.; SCHABAT, F.MM; LUNKES, E.F.; LUTINSKI, J.A.; CORRALLO, V.S. Incidência da leptospirose e fatores associados no município de Chapecó (SC). Revista de Epidemiologia e Controle de Infecção, v.7, n.4, p.221-226, 2017.

CEPED - Centro Universitário de Estudos e Pesquisas sobre Desastres Atlas brasileiro de desastres naturais 1991 a 2010: volume Brasil. Florianópolis: CEPED/UFSC; 2012.

CHAIBLICH, J.V.; LIMA, M.L.S.; OLIVEIRA, R.F.; MONKEN, M.; PENNA, M.L.F. Estudo espacial de riscos à leptospirose no município do Rio de Janeiro (RJ). Saúde em Debate, v.41, n.2, p.225-240, 2017.

CLAZER, M.; RODRIGUES, G.V.; ARAÚJO, L.; LOPES, K.F.C.; ZANIOLO, M.M.; GERBASI, A.R.VV.; GONÇALVES, D.D. Leptospirose e seu aspecto ocupacional - revisão de literatura. Arquivos de Ciências Veterinárias e Zoologia da UNIPAR, v.18, n.3, p.191-198, 2015.

COELHO, M.S.; MASSAD, E. The impact of climate on Leptospirosis in São Paulo, Brazil. International Journal of Biometeorology, v.56, p.233-241, 2012.

CONFALONIERI, U.E.C. Variabilidade climática, vulnerabilidade social e saúde no Brasil. Terra Livre, v.19, p.193-204, 2003.

COSTA, E.; COSTA, Y.A.; LOPES, A.A.; SACRAMENTO, E.; BINA, J.C. Formas graves de leptospirose: aspectos clínicos, demográficos e ambientais. Revista da Sociedade Brasileira de Medicina Tropical, v.34, n.3, p.261-267, 2001.

DE PAULA, E.V. Leptospirose humana: uma análise climato-geográfica de sua manifestação no Brasil, Paraná e Curitiba. In: XII Simpósio Brasileiro de Sensoriamento Remoto, Anais, Goiânia, 2005. 
DULAC, V.F.; KOBIYAMA, M. Interfaces entre políticas relacionadas a estratégias para redução de riscos de desastres: recursos hídricos, proteção e defesa civil e saneamento. REGA, v.14, e10, 2017.

DUTRA, F.R.L.S.; VALADÃO, R.C.; CONFALONIERI, U.E.; MULLER, G.V.; QUADRO, M.F.L. A influência da variabilidade da precipitação no padrão de distribuição dos casos de leptospirose em Minas Gerais no período de 1998 - 2012. Hygeia - Revista Brasileira de Geografia Médica e da Saúde, v.11, n.20, p.106-126, 2015.

FRANCA, R.R.; MENDONÇA, F.A. A cheia histórica do Rio Madeira no ano de 2014: riscos e impactos à saúde em Porto Velho (RO). Hygeia - Revista Brasileira de Geografia Médica e da Saúde, v.11, n.21, p.62-79, 2015.

FRANK, B.; SEVEGNANI, L. Desastre de 2008 no Vale do Itajaí. Água, gente e política. Blumenau: Agência de Água do Vale do Itajaí; 2009. 192p.

FREIRE, N.C.; BONFIM, C.V.; NATENZON, C.E. Vulnerabilidade socioambiental, inundações e repercussões na Saúde em regiões periféricas: o caso de Alagoas, Brasil. Ciência \& Saúde Coletiva, v.19, n.9, p.3755-3762, 2014.

FREITA, C.M.; CARVALHO, M.L.; XIMENES, E.F.; ARRAES, E.F.; GOMES, J.O. Vulnerabilidade socioambiental, redução de riscos de desastres e construção da resiliência - lições do terremoto no Haiti e das chuvas fortes na Região Serrana, Brasil. Ciência \& Saúde Coletiva, v.179, n.6, p.1577-1586, 2012.

GOERL, R.F.; KOBIYAMA, M. Considerações sobre as inundações no Brasil. In: Simpósio Brasileiro de Recursos Hídricos; Anais, João Pessoa/PB,2005.

GONÇALVES, N.V.; ARAÚJO, E.M.; SOUZA JÚNIOIR, A.S.; PEREIRA, W.M.M.; MIRANDA, C.S.C.; CAMPOS, P.S.S.; MATOS, M.W.S.; PALÁCIOS, V.R.C.M. Distribuição espaçotemporal da leptospirose e fatores de risco em Belém, Pará, Brasil. Ciência \& Saúde Coletiva, v.21, n.12, p.3947-3955, 2016.

GREICE, R.; BARCELLOS, C.; MAGALHÃES, M.; SOUZA-SANTOS, R.; BARROCAS, P.R.G. Geographical scale effects on the analysis of leptospirosis determinants. International Journal of Environmental Research and Public Health, v.11, p.1036610383, 2014.

GUIMARÃES, R.M.; CRUZ, O.G.; PARREIRA, V.G.; MAZOTO, M.L.; VIEIRA, J.D.; ASMUS, C.I.R.F. Análise temporal da relação entre leptospirose e ocorrência de inundações por chuvas no município do Rio de Janeiro, 2007-2012. Ciência \& Saúde Coletiva, v.19, n.9, p.3683-3692, 2014.

KO, A.I.; REIS, M.G.; DOURADO, C.M.R.; JOHNSON, W.D.; RILEY, L.W. Urban epidemic of severe leptospirosis in Brazil. The Lancet, v.354, p.820-825, 1999.

LONDE, L.R.; COUTINHO, M.P.; DI GREGÓRIO, L.T.; SANTOS, L.B.L.; SORIANO, E. Desastres relacionados à água no Brasil: perspectivas e recomendações. Ambiente \& Sociedade, v.17, n.4, p.133-152, 2014.

LONDE, L.R.; MARCHEZINI, V.; CONCEIÇÃO, R.S.; BORTOLETTO, K.C.; SILVA, A.E.P.; SANTOS, E.V.; REANI, R.T. Impactos de desastres socioambientais em saúde pública: estudos dos casos dos Estados de Santa Catarina em 2008 e Pernambuco em 2010. Revista Brasileira de Estudos de População, v.32, p.537-562, 2015. 
LONDE, L.R.; CONCEIÇÃO, R.S.; BERNARDES, T.; DIAS, M.C.A. Flood-related leptospirosis outbreaks in Brazil: perspectives for a joint monitoring by health services and disaster monitoring centers. Natural Hazards Review, v.84, n.2, p.1419-1435, 2016.

MAGALHÃES, G.B.; ZANELLA, M.E.; SALES, M.C.L. A ocorrência de chuvas e a incidência de leptospirose em Fortaleza/CE. Hygeia - Revista Brasileira de Geografia Médica e da Saúde, v.5, n.9, p.77-87, 2009.

MELO, C.B.; REIS, R.B.; KO, A.I.; BARRETO, C.M.N.; LIMA, A.P.; SILVA, A.M. Espacialização da leptospirose em Aracaju, Estado de Sergipe, no período de 2001 a 2007. Revista da Sociedade Brasileira de Medicina Tropical, v.44, n.4, p.475-480, 2011.

MINERVINO, A.C.; DUARTE, E.C. Danos materiais causados à Saúde Pública e à sociedade decorrentes de inundações e enxurradas no Brasil, 2010-2014: dados originados dos sistemas de informação global e nacional. Ciência \& Saúde Coletiva, v.21, p.685-694, 2016.

MINISTÉRIO DA SAÚDE. Portal Saúde: dados de situação epidemiológica. Disponível em http://portalsaude.saude.gov.br/index.php/situacao-epidemiologica-dados. Acesso em agosto de 2018.

OLIVEIRA, M. Campanha nacional "Hospitais seguros frente aos desastres - Reduzir riscos, proteger instalações de saúde, salvar vidas”. Florianópolis: CEPED/UFSC; 2009.

OLIVEIRA, V.M. Leptospirose na região Nordeste do Brasil: levantamento epidemiológico até 2010. In: VII Congresso Norte e Nordeste de Pesquisa e Inovação, Anais, Palmas/TO, 2012.

OLIVEIRA, D.S.C.; GUIMARÃES, M.J.B.; MEDEIROS, Z. Modelo produtivo para a leptospirose. Revista de Patologia Tropical, v.38, p.17-26, 2009.

OLIVEIRA, T.V.S.; NETO, C.C.; MARINHO, D.P.; KLIGERMAN, D.C. Variáveis climáticas, condições de vida e saúde da população: a leptospirose no município do Rio de Janeiro de 1996 a 2009. Ciência \& Saúde Coletiva, v.17, p.1569-1576, 2012.

PELLISSARI, D.M.; MAIA-ELKHOURY, A.N.S.; ARSKY, M.L.N.S.; NUNES, M.L. Revisão sistemática dos fatores associados à leptospirose no Brasil, 2000-2009. Epidemiologia e Serviços de Saúde, v.20, p.565-574, 2011.

PEREIRA, C.A.R. Custo social da leptospirose no Brasil e o efeito de chuvas extremas em Nova Friburgo para o incremento de casos da doença. 2014. Dissertação (Mestrado em Ciências na área de Saúde Pública e Meio Ambiente) - Escola Nacional de Saúde Pública Sergio Arouca, Rio de Janeiro, 2014.

REIS, R.B.; RIBEIRO, G.S.; FELZEMBURGH, R.D.M.; SANTANA, F.S.; MOHR, S. Impact of environment and social gradiente on leptospira infection in urban slums. PLoS-NTD, v.2, n.4, p.e228, 2008.

SANTOS, I.O.C. Caracterização ecoepidemiológica da leptospirose humana no Distrito Federal. 2016. Tese (Doutorado em Saúde Animal), Universidade de Brasília, Brasília, 2016.

SANTOS, L.; ASSIS, M.C.; SILVA, A.E.; ANGELIS,C.F. Sobre risco, ameaça e vulnerabilidade à leptospirose em situações pós-alagamentos, inundações e enxurradas: reconstruindo o episódio do Vale do Itajaí (2008-2009). In: I Congresso Brasileiro sobre Desastres Naturais, Anais, Rio Claro/SP, 2012.10p. 
SCHNEIDER, M.C.; NAJERA, P.; PEREIRA, M.M.; MACHADO, G.; ANJOS, C.B.; RODRIGUES, R.O.; CAVAGNI, G.M.; MUÑOZ-ZANZI, C.; CORBELLINI, L.G.; LEONE, M.; BUSS, D.F.; ALDIGHIERI, S.; ESINAL, M.A. Leptospirosis in Rio Grande do Sul, Brazil: ecosystem approach in the animal-human interface. PLoS-NTD, v.12, n.9, p.1-20, 2015.

SILVA, P.R. Relações entre a incidência de leptospirose e eventos de inundações urbanas em São José (SC). 2013. Trabalho de conclusão de curso (Graduação em Engenharia Sanitária e Ambiental), Universidade Federal de Santa Catarina, Florianópolis, 2013.

SILVA, P.L.; MOREIRA, S.M. Leptospirose: fatores ambientais que favorecem a sua ocorrência em humanos. Acervo da Iniciação Científica, n.1, p.1-14, 2013.

SIQUEIRA, J.A.S.; ALENCAR, L.D.; CAVALCANTE, L.P.S. Impactos da urbanização desordenada na saúde pública: leptospirose e infraestrutura urbana. Revista Eletrônica Polêmica, v.13, n.1, p.1006-1020, 2014.

SOARES, T.S.M.; LATORRE, M.R.D.O.; LAPORTA, G.Z.; BUZZAR, M.R. Análise espacial e sazonal da leptospirose no município de São Paulo, SP, 1998 a 2006. Cadernos de Saúde Pública, v.44, p.283-291, 2010.

SOUZA, D. Considerações sobre inundações e leptospirose humana no município de São Paulo. Revista da Escola de Enfermagem da USP, v.20, n.3, p.243-250, 1986.

SOUZA, R.; NASCIMENTO, S.L. Doenças e agravos no contexto das grandes inundações graduais no Estado do Amazonas. Hygeia - Revista Brasileira de Geografia Médica e da Saúde, v.13, n.26, p.139-147, 2017.

TASSINARI, W.S.; PELLEGRINI, D.C.P.; SABROZA, P.C.; CARVALHO, M.S. Distribuição espacial da leptospirose no Município do Rio de Janeiro, Brasil, ao longo dos anos de 19961999. Cadernos de Saúde Pública, v.20, p.1721-1729, 2004.

TOMINAGA, L.K.; SANTORO, J.; AMARAL, R. Desastres Naturais: conhecer para prevenir. São Paulo: Instituto Geológico; 2009.

VASCONCELOS, C.H.; FONSECA, F.R.; LISE, M.L.Z.; ARSKY, M.L.N.S. Fatores ambientais e socioeconômicos relacionados à distribuição de casos de leptospirose no estado de Pernambuco, Brasil, 2001- 2009. Ciência \& Saúde Coletiva, v.20, n.1, p.49-56, 2012.

\section{NOTAS DE AUTOR}

\section{CONTRIBUIÇÃO DE AUTORIA}

Francisco Carlos Portela - Concepção. Coleta de dados. Análise de dados. Elaboração do manuscrito. Masato Kobiyama - Concepção e elaboração do manuscrito. Participação ativa da discussão dos resultados. Revisão e aprovação da versão final do trabalho.

Roberto Fabris Goerl - Concepção e elaboração do manuscrito. Organização e análise de dados. Elaboração dos mapas. Participação ativa da discussão dos resultados. Revisão e aprovação da versão final do trabalho.

\section{FINANCIAMENTO}

Este projeto foi parcialmente financiado pela Chamada MCTIC/CNPq № 28/2018 - Universal, processo 434234/2018-4.

O segundo autor recebeu apoio de bolsa de Produtividade CNPq. 
PORTELA, KOBIYAMA, GOERL

APROVAÇÃO DE COMITÊ DE ÉTICA EM PESQUISA

Não se aplica

CONFLITO DE INTERESSES

Não há conflito de interesses

\section{LICENÇA DE USO}

Este artigo está licenciado sob a Licença Creative Commons CC-BY. Com essa licença você pode compartilhar, adaptar, criar para qualquer fim, desde que atribua a autoria da obra.

\section{HISTÓRICO}

Recebido em: 04-02-2019

Aprovado em: 06-05-2020 